\title{
A Novel Method of Fixation of Tracheostomy Tube in Cervical Spine Surgeries with Posterior Approach
}

Sir,

Securing of any external devices such as endotracheal tube (ETT), tracheostomy tube (TT), arterial and central venous catheters, nasogastric tubes, drainage tubes such as external ventricular drain, urinary catheters should be firm without being uncomfortable to the patients. Accidental dislodgement increases the possibility of replacing it subsequently with difficulty. Moreover, a life-threatening scenario can always be expected with dislodgement of endotracheal and TTs. This is usually seen in critical care settings where agitated patients wrench the ETT.

In the operating room (OR) settings, this scenario is relatively uncommon as the patient remains anesthetized. However, any surgery in prone position with TT in situ always increases the probability of accidental dislodgement. This is due to the effect of gravity superimposed by the weight of anesthetic breathing circuits during general anesthesia. This in turn demands properly securing TT so as to avoid accidental decannulation. Conventionally, TTs are secured with twill tapes which run through posterior part of the neck and held in position by applying knots (knot method). However, in surgeries of the cervical spine with posterior approach, this part of the tape obscures surgical field and needs to be removed. By far and common in surgeries of the cervical spine, the TT is held in front of the neck by sutures on either side (suture method). Even though uncommon, suturing might predispose to vessel injury apart from the cosmetic issues arising thereafter.

We have developed a slight modification of the conventional method where instead of making a knot, we stretch the twill tapes on the back, each running in front of the scapula and ending at infrascapular area on each side. This is followed by affixing the twill tapes on either side with adhesive tapes commonly available in the OR [Figure 1]. This helps to snuggly affix the TT in correct position [Figure 2]. At the same time, it avoids any impedance to the operation surgeon in the posterior aspect. This modification was applied in 20 patients of cervical spine surgery with the posterior approach with TT in situ. No undue complications such as injury or accidental dislodgement were noticed. Moreover, there is no extra expense involved in fixing the TT by this method as adhesive tapes are commonly available in the OR. Thus, from this correspondence, we would like to recommend the modified approach of securing TT in patients undergoing cervical spine surgery with the posterior approach.

\section{Financial support and sponsorship}

Nil.

\section{Conflicts of interest}

There are no conflicts of interest.

\section{Devendra Gupta, Ankur Khandelwal, Rudrashish Haldar \\ Department of Anaesthesiology, Sanjay Gandhi Post Graduate Institute of Medical Sciences, Lucknow, Uttar Pradesh, India}

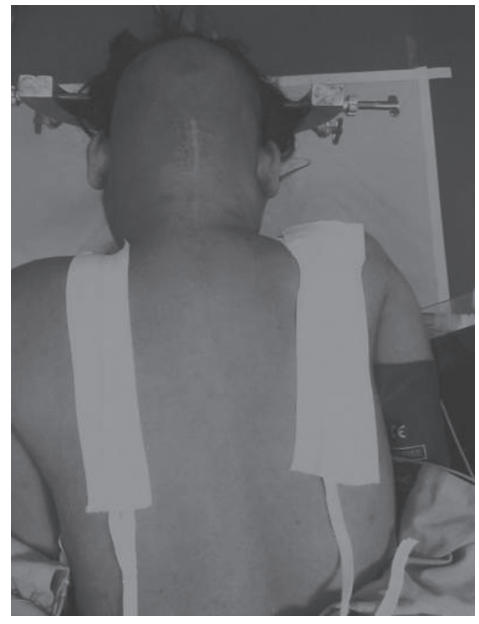

Figure 1: Posterior view image showing the modified approach of fixation of tracheostomy tube in cervical spine surgeries with posterior approach

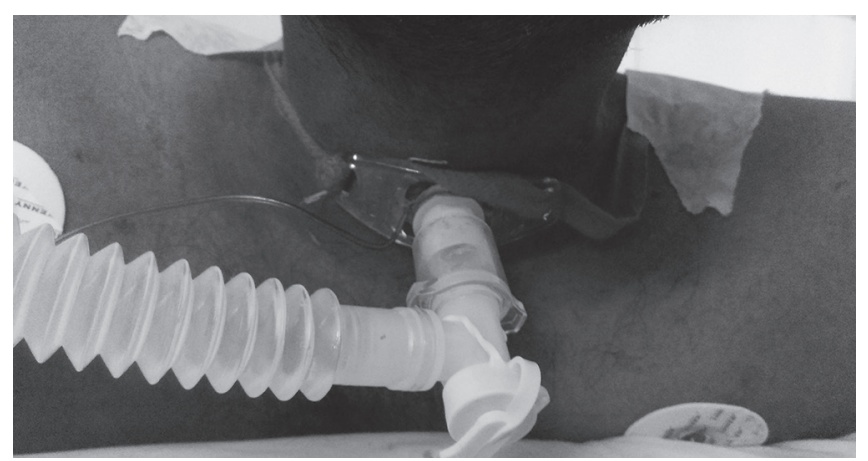

Figure 2: Anterior view image showing appropriately fixed tracheostomy tube with modified approach

Address for correspondence: Dr. Ankur Khandelwal, Department of Anaesthesiology, Sanjay Gandhi Post Graduate Institute of Medical Sciences, Rae Barelly Road, Lucknow - 226 014, Uttar Pradesh, India. E-mail: ankurchintus@gmail.com

This is an open access article distributed under the terms of the Creative Commons Attribution-NonCommercial-ShareAlike 3.0 License, which allows others to remix, tweak, and build upon the work non-commercially, as long as the author is credited and the new creations are licensed under the identical terms.

\begin{tabular}{|l|l|}
\hline \multicolumn{2}{|c|}{ Access this article online } \\
\hline Quick Response Code: & Website: \\
\hline
\end{tabular}

How to cite this article: Gupta D, Khandelwal A, Haldar R. A novel method of fixation of tracheostomy tube in cervical spine surgeries with posterior approach. J Neurosci Rural Pract 2016;7:S123. 